\title{
D-Dimer is a Predictive Factor of Cancer Therapeutics-Related Cardiac Dysfunction in Patients Treated With Cardiotoxic Chemotherapy
}

Masayoshi Oikawa ( $\square$ moikawa@fmu.ac.jp)

Fukushima Medical University

Daiki Yaegashi

Fukushima Medical University

Tetsuro Yokokawa

Fukushima Medical University

Tomofumi Misaka

Fukushima Medical University

Takamasa Sato

Fukushima Medical University

Takashi Kaneshiro

Fukushima Medical University

Atsushi Kobayashi

Fukushima Medical University

Akiomi Yoshihisa

Fukushima Medical University

Kazuhiko Nakazato

Fukushima Medical University

Takafumi Ishida

Fukushima Medical University

Yasuchika Takeishi

Fukushima Medical University

\section{Research}

Keywords: Cardio-Oncology, D-dimer, Cancer therapeutics-related cardiac dysfunction, Heart failure.

Posted Date: September 21st, 2021

DOl: https://doi.org/10.21203/rs.3.rs-900426/v1 
License: (c) (i) This work is licensed under a Creative Commons Attribution 4.0 International License. Read Full License

Version of Record: A version of this preprint was published at Frontiers in Cardiovascular Medicine on January 21st, 2022. See the published version at https://doi.org/10.3389/fcvm.2021.807754. 


\section{Abstract}

Background: D-dimer is a sensitive biomarker for cancer-associated thrombosis, but little is known about its significance on cancer therapeutics-related cardiac dysfunction (CTRCD).

Methods: Consecutive 169 patients planned for cardiotoxic chemotherapy were enrolled and followed up for 12 months. All patients underwent echocardiography and blood test at baseline, as well as at 3month, 6-month, and 12-month.

Results: The patients were divided into 2 groups based on the level of D-dimer $(>1.65 \mu \mathrm{g} / \mathrm{ml}$ or $\leqq 1.65$ $\mu \mathrm{g} / \mathrm{ml})$ at baseline before chemotherapy: High D-dimer group $(n=37)$ and low D-dimer group $(n=132)$. Left ventricular ejection fraction (EF) decreased at 3-month and 6-month after chemotherapy in high Ddimer group (baseline, 65.2\% [62.8\%-71.4\%]; 3-month, 62.9\% [59.0\%-67.7\%]; 6-month, 63.1\% [60.0\%-67.1\%]; 12-month, 63.3\% [58.8\%-66.0\%], P = 0.03), but no change was observed in low D-dimer group. The occurrence of CTRCD within the 12-month follow-up period was higher in high D-dimer group than in low $\mathrm{D}$-dimer group $(16.2 \%$ vs. $4.5 \%, \mathrm{P}=0.0146)$. Multivariable logistic regression analysis revealed that high D-dimer level at baseline was an independent predictor of the development of CTRCD (odds ratio $3.93,95 \% \mathrm{Cl}[1.00-15.82], \mathrm{P}=0.047)$.

Conclusion: Elevated D-dimer is a pivotal biomarker to predict CTRCD.

\section{Background}

Recent advances in the diagnosis and treatment of cancers improves its prognosis. However, anti-cancer drugs, including anthracyclines, monoclonal antibodies, tyrosine kinase inhibitors, and etc., induce cardiac dysfunction, resulting in poor prognosis in cancer survivors [1]. Several cardiac biomarkers and echocardiographic parameters, including troponins, myeloperoxidase, and reduced global longitudinal strain, are proposed to detect early phase of cancer therapeutics-related cardiac dysfunction (CTRCD), and prompt cardioprotective treatment can improve cardiac function [2-5]. Although those parameters are useful, careful monitoring is required to all patients to detect early sign of CTRCD. Thus, a novel biomarker that identifies high-risk patients before chemotherapy is desirable to perform effective clinical monitoring.

D-dimer is a sensitive biomarker for cancer-associated thrombosis, but accumulating evidence suggests that pretreatment D-dimer can be used as a prognostic biomarker for the patients with solid tumors [6]. In cardiovascular fields, elevated D-dimer is associated with not only thromboembolic events but also heart failure mortality in heart failure patients with reduced and preserved ejection fraction $[7,8]$.

Although D-dimer is a promising biomarker in cardio-oncology field, little is known about the relationship between D-dimer and CTRCD. The aim of the present study was to evaluate a predictive impact of Ddimer before chemotherapy on the development of CTRCD. 


\section{Methods}

\section{Study subjects and protocol}

We enrolled 202 consecutive cancer patients, planned for cardiotoxic chemotherapy, including anthracyclines, human epidermal growth factor receptor 2 (HER2) inhibitors, tyrosine kinase inhibitors, and proteasome inhibitors at Fukushima Medical University hospital from November 2016 to March 2019 (Figure 1). Patients were excluded if they were died or transferred to other hospitals within 12 months follow-up period ( $n=33$ ). Remaining 169 patients were divided into 2 groups based on the cut-off value of $D$-dimer, which was defined by receiver operator characteristic curve analysis to detect the occurrence of CTRCD (Figure 2).

Hypertension was defined as a history of use of antihypertensive drug or systolic blood pressure of $\geq 140$ $\mathrm{mmHg}$, and/or diastolic blood pressure $\geq 90 \mathrm{mmHg}$. Diabetes was defined as a recent use of insulin treatment or hypoglycemic drug, or hemoglobin $A 1 c \geq 6.5 \%$. Dyslipidemia was defined as a history of use of cholesterol-lowering drugs, or triglyceride was $\geq 150 \mathrm{mg} / \mathrm{dl}$, low density lipoprotein cholesterol was $\geq 140 \mathrm{mg} / \mathrm{dl}$, and/or high-density lipoprotein cholesterol was $\leq 40 \mathrm{mg} / \mathrm{dl}$. Cumulative dose of anthracycline was expressed as a doxorubicin equivalent [1]. HER2 inhibitor included trastuzumab and pertuzumab. Tyrosine kinase inhibitors included dabrafenib, trametinib, lenvatinib, sorafenib, dasatinib, bevacizumab, and pazopanib. Proteasome inhibitors included carfilzomib and bortezomib. Radiation therapy was defined as a irradiation to the mediastinum and/or the heart field within follow-up period. Transthoracic echocardiography and blood sampling test were performed at baseline, as well as at 3 months, 6 months, and 12 months after administration of cardiotoxic chemotherapy. All procedures used in this research were approved by the Ethical Committee of Fukushima Medical University.

\section{Echocardiography}

Transthoracic echocardiography was performed by a trained sonographer, and images were checked by another trained sonographer and an echo-cardiologist. We measured cardiac function using EPIQ 7G (Philips Healthtech, Best, Netherland). Left ventricular ejection fraction (EF) was calculated using the modified Simpson's method according to the guideline from the American Society of Echocardiography and the European Association of Cardiovascular Imaging [9]. The left ventricular (LV) mass was calculated using the following formula

\section{Left ventricular $(L V)$ mass $=0.8 \times[1.04 \times\{(L V$ diastolic diameter +}

\section{interventricular septum wall thicness $+\mathrm{LV}$ posterior wall thicness $)^{3}-$}

\section{$\left.\left.(\text { LV diastolic diameter })^{3}\right\}\right]+0.6 \mathrm{~g}[9]$.}

CTRCD was defined as a decrease in EF more than $10 \%$ points, to a value less than $53 \%$ [10]. LV enddiastolic volume index, LV end-systolic volume index, LV mass index, and left atrial volume index were 
measured using B-mode ultrasound.

\section{Blood sampling}

High sensitivity cardiac troponin I (Tnl) was measured using an assay based on Luminescent Oxygen Channeling Immunoassay technology, and run on a Dimension EXL integrated chemistry system (Siemens Healthcare Diagnostics, Deerfield, IL, USA). B-type natriuretic peptide (BNP) levels were measured using a specific immunoradiometric assay (Shionoria BNP kit, Shionogi, Osaka, Japan). Ddimer was measured using a latex agglutination method (Lias Auto D-dimer Neo, Sysmex, Kobe, Japan).

\section{Statistical analysis}

All statistical analyzes were performed using Prism 9 (GraphPad Software, San diego, USA) or R software packages version 3.6.3 (R core team 2020, Vienna, Austria). We used the Shapiro-Wilk test to discriminate which variables were normally or not normally distributed. Normally distributed variables were shown as mean \pm standard deviation. Non-normally distributed variables were indicated by median with interquartile range. Category variables were shown in numbers and percentage. Student's t-test was used for variables following a normal distribution, the Mann-Whitney U-test was used for variables of the nonnormal distribution, and the $\chi$-square test was used for categorical variables. The time course of EF (baseline, 3-month, 6-month, and 12-month after the administration of anthracyclines) was evaluated using the Friedman test.

Logistic regression analysis was performed to identify the variables to predict the occurrence of CTRCD. We selected variables relating to general condition and cardiac function, including age, echocardiographic parameters, use of anthracyclines, BNP, hemoglobin, estimated glomerular filtration ratio, and the elevation of D-dimer. The variables presenting $P$ value less than 0.05 in the univariable analysis were entered into the multivariable analysis. Receiver operating characteristic curve analysis was performed to determine the optimal cut-off value of D-dimer for predicting the occurrence of CTRCD. The $P$ value of 0.05 or less was defined as significant.

\section{Results}

First, we performed receiver operating characteristic curve analysis to identify the threshold level of Ddimer to predict the occurrence of CTRCD (Fig. 2). A total of 12 patients suffered CTRCD within 12 months follow-up period. When we set the cut-off value of D-dimer at $1.65 \mu \mathrm{g} / \mathrm{ml}$, sensitivity, specificity, and area under the curve to predict CTRCD were $50.0 \%, 80.3 \%$, and 0.661 , respectively. Then, we divided the patients into 2 groups based on the cut-off value. Table 1 shows patient characteristics at the baseline before chemotherapy. There were no statistical differences in age, sex, and the usage of angiotensin-converting enzyme inhibitors/angiotensin II receptor blockers and $\beta$-blockers. High D-dimer group included lower rate of breast cancer ( $35 \%$ vs. $67 \%, P=0.0005)$, higher rate of ovarian/uterine cancer $(19 \%$ vs. $6 \%, P=0.0151)$, and higher rate of leukemia ( $16 \%$ vs. $4 \%, P=0.0068)$ than low $D$-dimer group. Echocardiographic data demonstrated that EF was slightly higher in high D-dimer group (67 $\pm 5 \%$ 
vs. $64 \pm 5 \%, P=0.0019)$. In laboratory data, high $D$-dimer group showed lower hemoglobin values and higher BNP values. 
Table 1

Baseline clinical characteristics of patients with elevated or non-elevated D-dimer

\begin{tabular}{|c|c|c|c|c|}
\hline Variable & $\begin{array}{l}\text { Entire cohort ( } n \\
=169)\end{array}$ & $\begin{array}{l}\text { Low D-dimer ( } n \\
=132)\end{array}$ & $\begin{array}{l}\text { High D-dimer ( } \mathrm{n} \\
=37 \text { ) }\end{array}$ & $\begin{array}{l}\mathrm{P} \\
\text { value }\end{array}$ \\
\hline Age, years & $57 \pm 12$ & $56 \pm 12$ & $58 \pm 14$ & 0.6265 \\
\hline Female, n (\%) & $146(86 \%)$ & $117(89 \%)$ & $29(78 \%)$ & 0.1078 \\
\hline \multicolumn{5}{|l|}{ Medications } \\
\hline Use of ACEi or ARB & 23 & 18 & 5 & 0.9846 \\
\hline Use of $\beta$-blockers & 4 & 3 & 1 & 0.8791 \\
\hline \multicolumn{5}{|l|}{ Cancer types } \\
\hline Breast cancer, n (\%) & $101(60 \%)$ & $88(67 \%)$ & $13(35 \%)$ & 0.0005 \\
\hline Lymphoma, n (\%) & $28(17 \%)$ & $20(15 \%)$ & $8(22 \%)$ & 0.3495 \\
\hline $\begin{array}{l}\text { Ovarian or uterine cancer, } \mathrm{n} \\
(\%)\end{array}$ & $15(9 \%)$ & $8(6 \%)$ & $7(19 \%)$ & 0.0151 \\
\hline Leukemia, n (\%) & $11(7 \%)$ & $5(4 \%)$ & $6(16 \%)$ & 0.0068 \\
\hline Bone cancer, n (\%) & $2(2 \%)$ & $2(2 \%)$ & $0(0 \%)$ & 0.4513 \\
\hline Other cancers, n (\%) & $12(7 \%)$ & $9(7 \%)$ & $3(8 \%)$ & 0.7872 \\
\hline \multicolumn{5}{|l|}{ Cancer therapy } \\
\hline Anthracyclines & $138(82 \%)$ & $104(79 \%)$ & $34(92 \%)$ & 0.0687 \\
\hline HER2 inhibitors & $36(21 \%)$ & $31(23 \%)$ & $5(14 \%)$ & 0.1905 \\
\hline Tyrosine kinase inhibitors & $8(5 \%)$ & $6(5 \%)$ & $2(5 \%)$ & 0.8277 \\
\hline Proteasome inhibitors & $5(3 \%)$ & $5(4 \%)$ & $0(0 \%)$ & 0.2295 \\
\hline $\begin{array}{l}\text { Dose of anthracyclines } \\
\text { (doxorubicin equivalent), } \\
\mathrm{mg} / \mathrm{m}^{2}\end{array}$ & 200 [161-240] & 200 [180-240] & 180 [112-300] & 0.3874 \\
\hline Radiation therapy, n (\%) & $20(12 \%)$ & $15(11 \%)$ & $5(14 \%)$ & 0.7205 \\
\hline \multicolumn{5}{|l|}{ Cardiovascular risk factors } \\
\hline Hypertension, n (\%) & $40(24 \%)$ & $31(24 \%)$ & $9(24 \%)$ & 0.9154 \\
\hline Smoking history, n (\%) & $47(28 \%)$ & $37(28 \%)$ & $10(27 \%)$ & 0.9042 \\
\hline Diabetes mellitus, n (\%) & $16(10 \%)$ & $13(10 \%)$ & $3(8 \%)$ & 0.7493 \\
\hline
\end{tabular}




\begin{tabular}{|c|c|c|c|c|}
\hline Variable & $\begin{array}{l}\text { Entire cohort (n } \\
=169)\end{array}$ & $\begin{array}{l}\text { Low D-dimer ( } \\
=132)\end{array}$ & $\begin{array}{l}\text { High D-dimer (n } \\
=37)\end{array}$ & $\begin{array}{l}P \\
\text { value }\end{array}$ \\
\hline Dyslipidemia, n (\%) & $44(26 \%)$ & $38(29 \%)$ & $6(16 \%)$ & 0.1235 \\
\hline \multicolumn{5}{|l|}{ Atrial fibrillation, n (\%) } \\
\hline \multicolumn{5}{|l|}{ Echocardiographic parameter } \\
\hline $\begin{array}{l}\text { LV end-diastolic volume index, } \\
\mathrm{mm} / \mathrm{m}^{2}\end{array}$ & $45[36-55]$ & $45[36-55]$ & $46[36-55]$ & 0.6517 \\
\hline $\begin{array}{l}\text { LV end-systolic volume index, } \\
\mathrm{mm} / \mathrm{m}^{2}\end{array}$ & 15 [13-20] & 15 [13-19] & $16[12-20]$ & 0.6431 \\
\hline LV mass index, $\mathrm{g} / \mathrm{m}^{2}$ & $70[59-85]$ & $70[59-85]$ & $75[60-87]$ & 0.4644 \\
\hline LA volume index, $\mathrm{ml} / \mathrm{m}^{2}$ & $23[17-30]$ & $23[17-28]$ & $23[19-32]$ & 0.3159 \\
\hline LV ejection fraction, \% & $65 \pm 5$ & $64 \pm 5$ & $67 \pm 5$ & 0.0019 \\
\hline $\mathrm{E} / \mathrm{A}$ & $1.0[0.8-1.2]$ & $1.0[0.8-1.2]$ & $0.9[0.8-1.1]$ & 0.5788 \\
\hline \multicolumn{5}{|l|}{ Laboratory data } \\
\hline $\begin{array}{l}\text { Aspartate aminotransferase, } \\
\text { IU/L }\end{array}$ & 19 [15-23] & 19 [16-23] & 19 [15-26] & 0.7973 \\
\hline $\begin{array}{l}\text { Alanine aminotransferase, } \\
\text { IU/L }\end{array}$ & 15 [12-22] & 15 [12-21] & 15 [12-23] & 0.7960 \\
\hline eGFR, $\mathrm{ml} / \mathrm{min} / 1.73 \mathrm{~m}^{2}$ & 72 [64-85] & $73[65-82]$ & $69[57-88]$ & 0.3472 \\
\hline Hemoglobin, g/dl & $13[11-14]$ & $13[12-14]$ & $11[9-13]$ & 0.0001 \\
\hline Uretic acid, mg/dl & $4.7 \pm 1.4$ & $4.6 \pm 1.3$ & $4.7 \pm 1.7$ & 0.8197 \\
\hline $\begin{array}{l}\text { B-type natriuretic peptide, } \\
\mathrm{pg} / \mathrm{ml}\end{array}$ & $12[7-22]$ & $11[7-20]$ & $17[9-38]$ & 0.0440 \\
\hline Troponin I, ng/ml & $\begin{array}{l}0.017[0.017- \\
0.017]\end{array}$ & $\begin{array}{l}0.017[0.017- \\
0.017]\end{array}$ & $\begin{array}{l}0.017[0.017- \\
0.017]\end{array}$ & 0.5440 \\
\hline D-dimer, $\mu \mathrm{g} / \mathrm{ml}$ & $0.6[0.5-1.4]$ & $0.5[0.5-0.7]$ & $3.1[2.2-8.1]$ & $<.0001$ \\
\hline
\end{tabular}

Time-dependent changes in EF are displayed in Fig. 3. Low D-dimer group showed no changes in EF within follow-up period, but EF was decreased at 3-month and 6-month after chemotherapy in high Ddimer group (baseline, 65.2\% [62.8\%-71.4\%]; 3-month, 62.9\% [59.0\%-67.7\%]; 6-month, 63.1\% [60.0\%-67.1\%]; 12-month, 63.3\% [58.8\%-66.0\%], P = 0.03, Fig. 3A and 3B). 
The occurrence of CTRCD during the 12-month follow-up period was higher in high D-dimer group than in low $\mathrm{D}$-dimer group $(16.2 \%$ vs. $4.5 \%, \mathrm{P}=0.0146)$. Multivariable logistic regression analysis revealed that $\mathrm{LV}$ end-diastolic volume index (odds ratio $0.95,95 \% \mathrm{Cl}$ [0.91-0.99], $\mathrm{P}=0.0122$ ) and high D-dimer levels (odds ratio $3.93,95 \% \mathrm{Cl}$ [1.00-15.82], $\mathrm{P}=0.0469$ ) before chemotherapy were independent predictors of the development of CTRCD (Table 2).

Table 2

Parameters associated with the occurrence of CTRCD

\begin{tabular}{|c|c|c|c|c|}
\hline & \multicolumn{2}{|l|}{ Univariate } & \multicolumn{2}{|l|}{ Multivariate } \\
\hline & OR $(95 \% \mathrm{Cl})$ & $\begin{array}{l}P \\
\text { value }\end{array}$ & OR $(95 \% \mathrm{Cl})$ & $\begin{array}{l}P \\
\text { value }\end{array}$ \\
\hline Age, per 1 year increase & $\begin{array}{l}1.01(0.96- \\
1.05)\end{array}$ & 0.8470 & & \\
\hline Male & $\begin{array}{l}1.79(0.32- \\
33.57)\end{array}$ & 0.5852 & & \\
\hline Use of anthracyclines & $\begin{array}{l}1.18(0.29- \\
7.94)\end{array}$ & 0.8353 & & \\
\hline $\mathrm{BNP}$, per $1 \mathrm{pg} / \mathrm{ml}$ increase & $\begin{array}{l}0.99(0.98- \\
1.02)\end{array}$ & 0.4239 & & \\
\hline LV ejectioin fraction, per $1 \%$ increase & $\begin{array}{l}1.07(0.95- \\
1.22)\end{array}$ & 0.2591 & & \\
\hline $\begin{array}{l}\text { LV end-diastolic volume index, per } 1 \mathrm{ml} / \mathrm{m}^{2} \\
\text { increase }\end{array}$ & $\begin{array}{l}0.95(0.91- \\
0.99)\end{array}$ & 0.0099 & $\begin{array}{l}0.95(0.91- \\
0.99)\end{array}$ & 0.0122 \\
\hline E/A, per 1 increase & $\begin{array}{l}0.24(0.05- \\
1.39)\end{array}$ & 0.0934 & & \\
\hline $\begin{array}{l}\text { Left atrial volume index, per } 1 \mathrm{ml} / \mathrm{m}^{2} \\
\text { increase }\end{array}$ & $\begin{array}{l}0.99 \\
1.05)\end{array}(0.94-$ & 0.7157 & & \\
\hline Hemoglobin, per $1 \mathrm{~g} / \mathrm{dl}$ increase & $\begin{array}{l}1.13(0.85- \\
1.45)\end{array}$ & 0.3539 & & \\
\hline Estimated GFR, per $1 \mathrm{ml} / \mathrm{min} / 1.73 \mathrm{~m}^{2}$ & $\begin{array}{l}0.98(0.95- \\
1.02)\end{array}$ & 0.2989 & & \\
\hline Elevated D-dimer (1.65 mg/dl) & $\begin{array}{l}4.07(1.20- \\
13.84)\end{array}$ & 0.0218 & $\begin{array}{l}3.93(1.00- \\
15.82)\end{array}$ & 0.0469 \\
\hline
\end{tabular}

\section{Discussion}


In the present study, we revealed the predictive features of D-dimer in patients treated with cardiotoxic agents. First, the threshold level of D-dimer was $1.65 \mu \mathrm{g} / \mathrm{ml}$ to predict the development of CTRCD. Second, EF was decreased time dependently in high D-dimer patients. Third, the occurrence CTRCD was significantly higher in high D-dimer patients.

D-dimer is a pivotal biomarker of hypercoagulability and thrombosis. Fibrin-bound plasmin degrades the fibrin network into soluble fragments D-dimers and E fragments, thus increased levels of D-dimer represent a global activation of coagulation and fibrinolysis [11]. Cancers produce hypercoagulable and prothrombotic situation by secreting several pro-thromboembolic factors such as mucins, cysteine protease, and tissue factors [12]. Therefore, thrombi are easily generated in cancer patients, and thromboembolism is the second leading cause of cancer related morbidity and mortality $[13,14]$. Although D-dimer is an established and widely used biomarker for the screening of thrombus formation in cancer patients, prognostic features of D-dimer become clinically overt recently. The link between Ddimer and cancer progression is reported in several papers $[15,16]$, and higher levels of D-dimer is associated with poor prognosis in cancer patients [16]. Although the precise mechanisms are still complex and uncovered, pro-coagulable state may produce a suitable milieu for cancer progression by recruitment of pro-metastatic leukocytes, adhesion to the endothelium, transendothelial migration, and restriction in natural killer cell-mediated clearance of micrometastasis $[17,18]$. Accumulating evidence showed that abnormal inflammation and oxidative stress are key factors to the development of heart failure, and those also play important roles in cancer progression and thrombus formation [19-23]. The inflammatory microenvironment is now recognized as an important participant or a regulator of all stages of tumor development, from an early stage of carcinogenesis to tumor promotion and metastatic spread to distant organs [22]. Regarding to thrombus formation, Gomes et al. reported that blockade of IL-1 receptor abolished the neutrophil extracellular traps-dependent prothrombotic state and attenuated cancer-associated thrombosis in murine breast cancer model [23]. Consider the facts that inflammation is a major contributor of cardiac dysfunction and thrombus formation, cancer patients with high D-dimer may be predispose to cardiac dysfunction due to chronic inflammatory state. Cardiotoxic chemotherapeutic agents are crucial and indispensable to perform cancer treatment. Anthracyclines induce pro-inflammatory response by increasing TNF-a, IL-1 $\beta$, and IL-6, leading to tumor cell death [24]. Not only anthracyclines, but targeted chemotherapy, such as trastuzumab and bevacizumab, also increased inflammatory cytokines after the treatment $[25,26]$. In the present study, the patients with high D-dimer group may already had been exposed to inflammatory state before chemotherapy, and were vulnerable to additional inflammatory stress by cardiotoxic agents, resulting in the development of CTRCD. To elucidate the precise mechanisms was beyond of this study, but the importance of D-dimer should be noted in cardio-oncology field. LIPID study revealed that elevated D-dimer levels predict longterm risk of arterial and venous events, cardiovascular disease mortality, in addition to that, increased cancer incidence and mortality rate [27]. To the best of our knowledge, this is the first report of assessing the relationship between D-dimer levels and the development of CTRCD. The importance of D-dimer should be taken into account when managing cancer patients treated with cardiotoxic chemotherapy. 


\section{Conclusions}

Elevated D-dimer is a pivotal biomarker to predict CTRCD. D-dimer should be taken into account when managing cancer patients treated with cardiotoxic chemotherapy.

\section{Limitations}

This study was performed using a relatively small number of patients and short follow-up period by a single center. Longer follow-up and larger population data were needed to confirm the importance of Ddimer to the development of CTRCD and cardiovascular prognosis.

\section{List Of Abbreviations}

CTRCD

Cancer therapeutics-related cardiac dysfunction; EF:Left ventricular ejection fraction; HER2:human epidermal growth factor receptor 2; LV:Left ventricular; Tnl:Troponin I; BNP:B-type natriuretic peptide.

\section{Declarations}

\section{Acknowledgement}

The authors thank for Ms. H. Kobayashi for data management.

\section{Authors' contributions}

MO created the study design, analyzed the data, and drafted the manuscript; DY created the study design and analyzed the data; TM, TS, TK, and AK aquired the data. AY, KN, TI, and YT interpreted the data, revised the manuscript. All authors contributed to the conception, design, critical revision and final approval of this manuscript.

\section{Funding}

There was no funding or financial support for this report.

\section{Availability of data and materials}

The datasets used and/or analyzed during the current study are available from the corresponding author on reasonable request.

\section{Ethics approval and consent to participate}

We obtained prior approval that the study protocol conformed to the ethical guidelines of the 1975 Declaration of Helsinki from the Ethics Committee of Fukushima Medical University (approval number 2839). Written consent was acquired from all patients. 


\section{Consent for publication}

Not applicable.

\section{Competing interests}

None of the authors have any competing interest to disclose.

\section{Author details}

Department of Cardiovascular Medicine, Fukushima Medical University, 1-Hikarigaoka, Fukushima, Fukushima 960-1295, Japan

\section{References}

1. Zamorano JL, Lancellotti P, Munoz DR, Aboyans V, Asteggiano R, Galderisi M, et al. 2016 ESC Position Paper on cancer treatments and cardiovascular toxicity developed under the auspices of the ESC committee for practice guidelines: The Task Force for cancer treatments and cardiovascular toxicity of the European Society of Cardiology (ESC). Eur Heart J. 2016;37:2768-801.

2. Oikawa M, Yoshihisa A, Yokokawa T, Misaka T, Yaegashi D, Miyata M, et al. Cardiac troponin I predicts elevated B-type natriuretic peptide in patients treated with anthracycline-containing chemotherapy. Oncology. 2020;98:653-60.

3. Ky B, Putt M, Sawaya H, French B, Januzzi JL Jr, Sebag IA, et al. Early increases in multiple biomarkers predict subsequent cardiotoxicity in patients with breast cancer treated with doxorubicin, taxanes, and trastuzumab. J Am Coll Cardiol. 2014;63:809-16.

4. Thavendiranathan P, Negishi T, Somerset E, Negishi K, Penicka M, Lemieux J, et al. Strain-guided management of potentially cardiotoxic cancer therapy. J Am Coll Cardiol. 2021;77:392-401.

5. Cardinale D, Colombo A, Bacchiani G, Tedeschi I, Meroni CA, Veglia F, et al. Early detection of anthracycline cardiotoxicity and improvement with heart failure therapy. Circulation. 2015;131:19818.

6. Li W, Tang Y, Song Y, Chen SH, Sisliyan N, Ni M, et al. Prognostic role of pretreatment plasma D-dimer in patients with solid tumors: a systematic review and meta-analysis. Cell Physiol Biochem. 2018;45:1663-76.

7. Zhang $X$, Wang S, Sun L, Fang S, Yu B. Prognostic value of D-dimer in acute myocardial infarction complicated by heart failure with preserved ejection fraction. ESC Heart Fail. 2020;7:4118-25.

8. de Boer RA, Nayor M, deFilippi CR, Enserro D, Bhambhani V, Kizer JR, et al. Association of cardiovascular biomarkers with incident heart failure with preserved and reduced ejection fraction. JAMA Cardiol. 2018;3:215-24.

9. Lang RM, Badano LP, Mor-Avi V, Afilalo J, Armstrong A, Ernande L, et al. Recommendations for cardiac chamber quantification by echocardiography in adults: an update from the American Society 
of Echocardiography and the European Association of Cardiovascular Imaging. J Am Soc Echocardiogr. 2015;28:1-39.

10. Plana JC, Galderisi M, Barac A, Ewer MS, Ky B, Scherrer-Crosbie M, et al. Expert consensus for multimodality imaging evaluation of adult patients during and after cancer therapy: a report from the American Society of Echocardiography and the European Association of Cardiovascular Imaging. J Am Soc Echocardiogr. 2014;27:911-39.

11. Kyrle PA, Eichinger S. D-dimer for long-term risk prediction in patients after acute coronary syndrome. Jack of all trades, or master of none? Circulation. 2018;138:724-6.

12. Varki A. Trousseau's syndrome: multiple definitions and multiple mechanisms. Blood. 2007;110:1723-9.

13. Prandoni P, Falanga A, Piccioli A. Cancer and venous thromboembolism. Lancet Oncol. 2005;6:40110.

14. Tuzovic M, Herrmann J, Iliescu C, Marmagkiolis K, Ziaeian B, Yang EH. Arterial thrombosis in patients with cancer. Curr Treat Options Cardiovasc Med. 2018;20:40.

15. Han D, ó Hartaigh B, Lee JH, Cho IJ, Shim CY, Chang HJ, et al. Impact of D-dimer for prediction of incident occult cancer in patients with unprovoked venous thromboembolism. PLoS One. 2016;11:e0153514.

16. Ay C, Dunkler D, Pirker R, Thaler J, Quehenberger P, Wagner O, et al. High D-dimer levels are associated with poor prognosis in cancer patients. Haematologica. 2012;97:1158-64.

17. Lucotti S, Muschel RJ. Platelets and Metastasis: New implications of an old interplay. Front Oncol. 2020;10:1350.

18. Palumbo JS, Talmage KE, Massari JV, La Jeunesse CM, Flick MJ, Kombrinck KW, et al. Tumor cellassociated tissue factor and circulating hemostatic factors cooperate to increase metastatic potential through natural killer cell-dependent and-independent mechanisms. Blood. 2007;110:13341.

19. Bertero E, Canepa M, Maack C, Ameri P. Linking heart failure to cancer: Background evidence and research perspectives. Circulation. 2018;138:735-42.

20. Koene RJ, Prizment AE, Blaes A, Konety SH. Shared risk factors in cardiovascular disease and cancer. Circulation. 2016;133:1104-14.

21. Barrera G. Oxidative stress and lipid peroxidation products in cancer progression and therapy. ISRN Oncol. 2012;2012:137289.

22. Jang JH, Kim DH, Surh YJ. Dynamic roles of inflammasomes in inflammatory tumor microenvironment. NPJ Precis Oncol. 2021;5:18.

23. Gomes T, Várady CBS, Lourenço AL, Mizurini DM, Rondon AMR, Leal AC, et al. IL-1 $\beta$ blockade attenuates thrombosis in a neutrophil extracellular trap-dependent breast cancer model. Front Immunol. 2019;10:2088. 
24. Tocchetti CG, Ameri P, de Boer RA, D'Alessandra Y, Russo M, Sorriento D, et al. Cardiac dysfunction in cancer patients: beyond direct cardiomyocyte damage of anticancer drugs: novel cardio-oncology insights from the joint 2019 meeting of the ESC Working Groups of Myocardial Function and Cellular Biology of the Heart. Cardiovasc Res. 2020;116:1820-34.

25. Dhesy-Thind S, Kumar V, Snider-McNair A, Shortt C, Mukherjee SD, Ellis P, et al. Cardiac and inflammation biomarker profile after initiation of adjuvant trastuzumab therapy. Clin Chem. 2013;59:327-9.

26. El-Hajjar L, Jalaleddine N, Shaito A, Zibara K, Kazan JM, El-Saghir J, et al. Bevacizumab induces inflammation in MDA-MB-231 breast cancer cell line and in a mouse model. Cell Signal. 2019;53:400-12.

27. Simes J, Robledo KP, White HD, Espinoza D, Stewart RA, Sullivan DR, et al. D-dimer predicts long-term cause-specific mortality, cardiovascular events, and cancer in patients with stable coronary heart disease: LIPID study. Circulation. 2018;138:712-23.

\section{Figures}

Figure 1

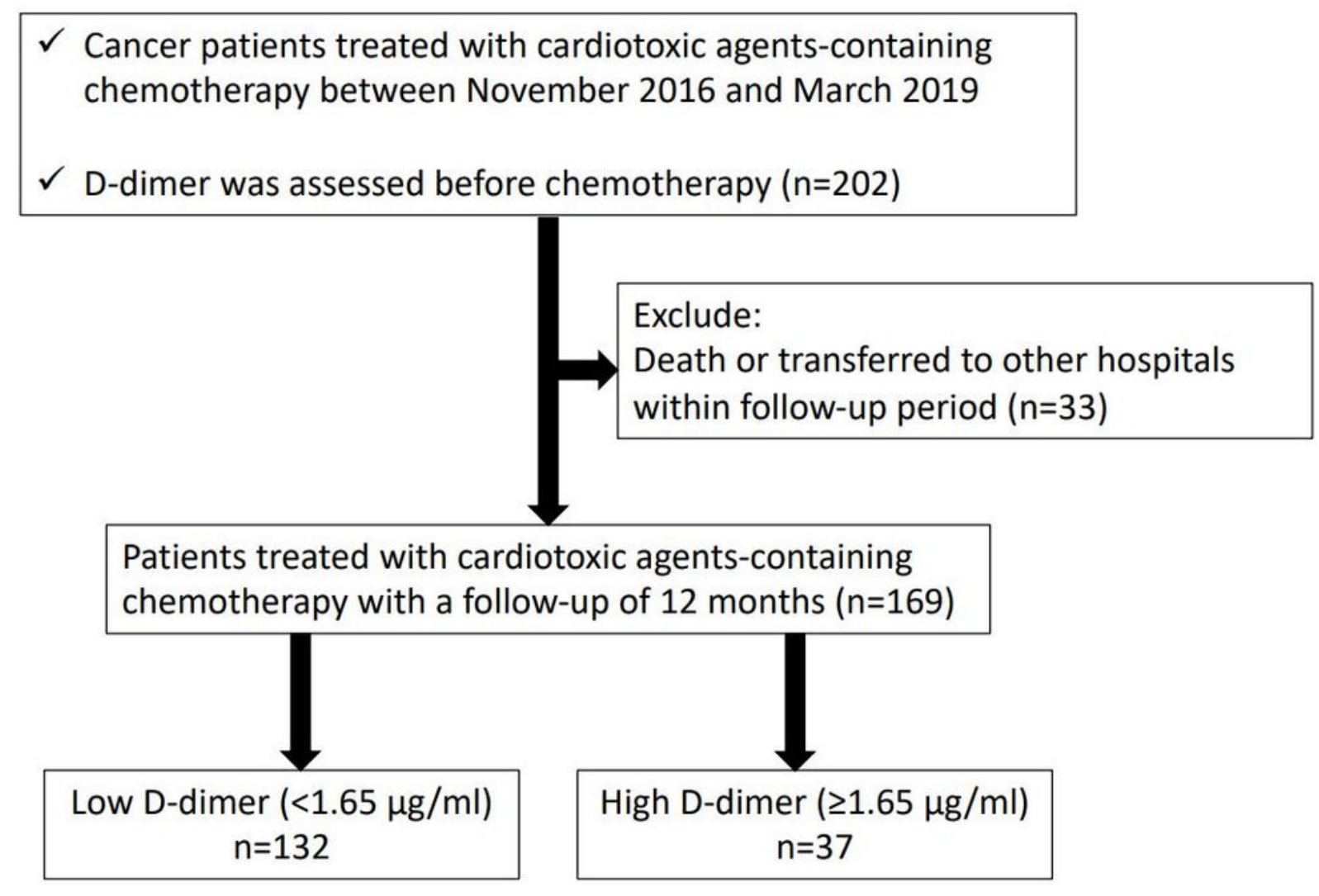

Figure 1 


\section{Figure 2}

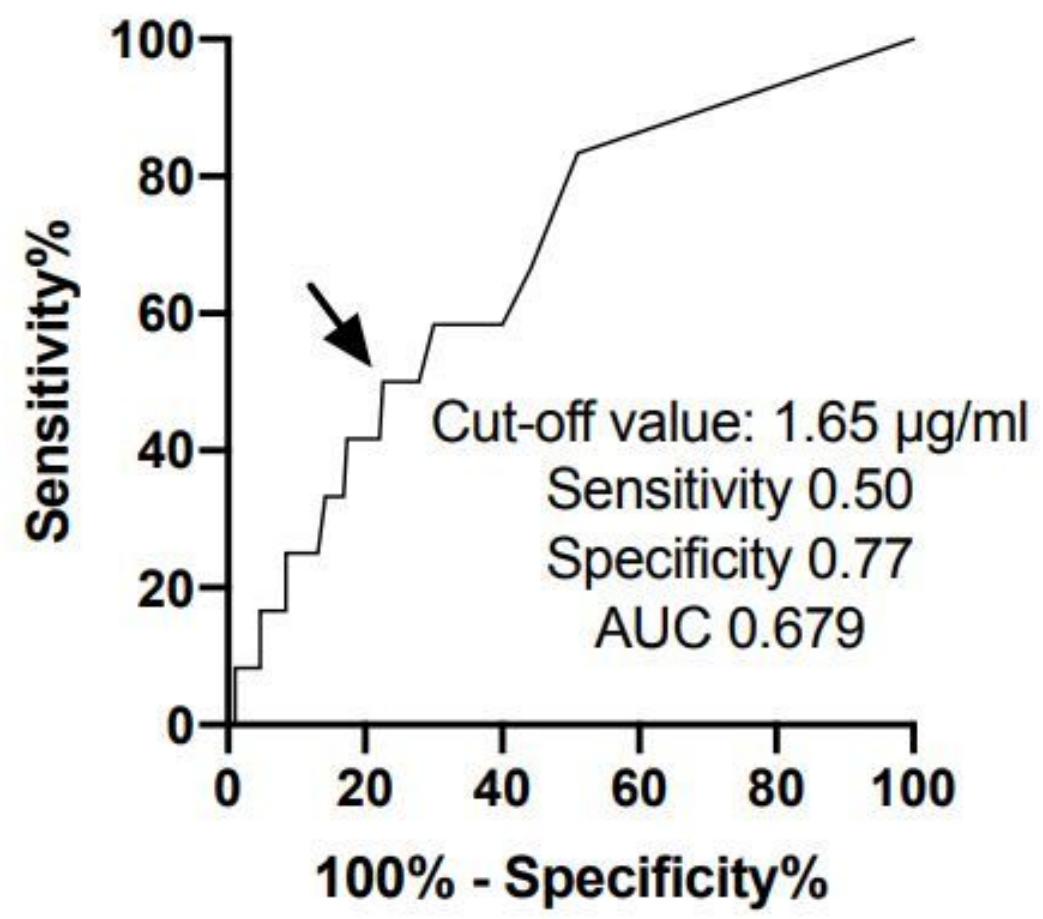

Figure 2

ROC curve analysis of D-dimer predicting the occurrence of cancer therapeutics-related cardiac dysfunction. 
Figure 3
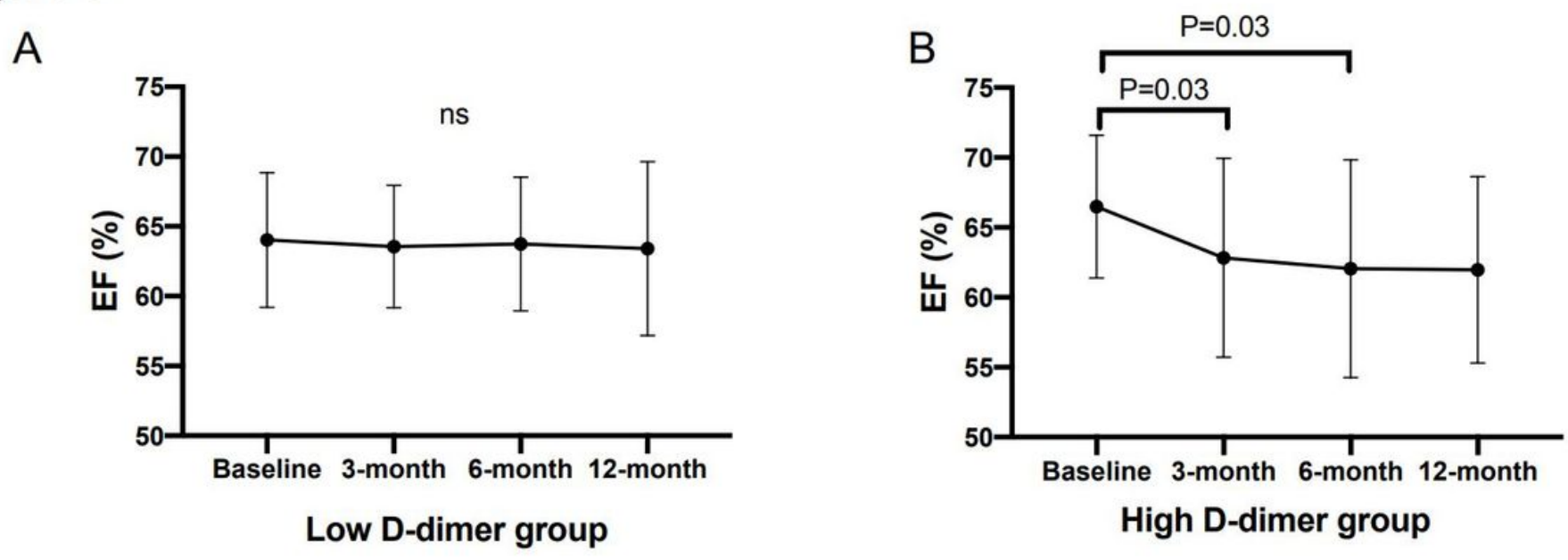

Figure 3

Time-dependent changes in EF after chemotherapy. (A) Changes in EF in low D-dimer group. (B) Changes in $\mathrm{EF}$ in high D-dimer group. 